\title{
LA CONFIGURACIÓN TEXTUAL DE LAS RECETAS MÉDICAS EN ESPAÑOL (SIGLOS XV-XVI)
}

Gabriela Cruz Volio

\section{(c) ${ }_{\mathrm{EY}} \mathrm{NO} \mathrm{ND}_{\mathrm{ND}}$}

Doi: https://doi.org/10.15517/rfl.v46iExt..43485

URL: https://revistas.ucr.ac.cr/index.php/filyling/index 



\title{
LA CONFIGURACIÓN TEXTUAL DE LAS RECETAS MÉDICAS EN ESPAÑOL (SIGLOS XV-XVI)
}

\author{
MEDICAL RECIPES AS TEXT TYPE AND GENRE IN SPANISH \\ (16TH AND 17TH CENTURIES)
}

\author{
Gabriela Cruz Volio
}

\begin{abstract}
RESUMEN
En este artículo presentamos un análisis de las recetas médicas en tanto género discursivo y tipo textual con el fin de contribuir con el estudio de la historia del español a través de la diversidad de sus formas discursivas. Con este objetivo, hemos seleccionado 557 recetas médicas de distintas obras de medicina escritas entre los siglos XV y XVI y las hemos analizado de acuerdo con los elementos estructurales (ingredientes, preparación, aplicación, eficacia), las formas verbales empleadas y el modo de incorporación de las recetas dentro del texto. Los resultados muestran que la presentación de información precisa y detallada, así como el empleo de infinitivos y perífrasis léxicas, se relaciona con obras cuya función es dar consejos y recomendaciones, mientras que la presentación de información vaga y el uso del imperativo es propio de las recetas que aparecen en libros dedicados a su compilación, los cuales están orientados a la consulta rápida e inmediata. Además, hemos definido que la elección de los patrones discursivos está determinada por el carácter de la obra, sea este erudito o extraacadémico.
\end{abstract}

Palabras clave: recetas médicas; pragmática histórica; género discursivo; tradiciones discursivas; historia del español.

\begin{abstract}
This article analyzes medical recipes as genre and text-type in order to gain more insight into the history of Spanish through the diversity of its texts and discourses. With this goal, we have selected 557 medical recipes from different works of medicine written in the fifteenth and sixteenth centuries and analyzed them according to the structural elements (ingredients, preparation, application, efficacy), the use of verbal forms and the incorporation of the recipes within the medical texts. The results show that precise and detailed information, as well as the use of infinitives and verbal periphrases, is related with medical works whose function lies in giving advice and recommendation, while vague information and the imperative mood is primarily used in remedy books and remedy sections, which are both destined for fast and immediate consultation. We conclude that the choices regarding discursive patterns is determined by whether the medical text is associated with the learned tradition or whether it is an extraacademic text.
\end{abstract}

Keywords: medical recipes; historical pragmatics; discourse genre; discourse traditions; history of Spanish.

Dra. Gabriela Cruz Volio. Profesora de la Escuela de Filología, Universidad de Costa Rica. San José, Costa Rica. Correo electrónico: gabriela.cruzvolio@ucr.ac.cr 


\section{La receta médica como género discursivo y tipo de texto ${ }^{1}$}

En la Península Ibérica, el siglo XV fue un período caracterizado por el aumento de la producción textual, como señalan Santiago (2005) y Eberenz (2001). Este incremento se observa no solo en la cantidad, sino también en la diversidad temática y tipológica de textos escritos en castellano, por lo cual Eberenz (2001) insiste en la importancia de este siglo para el desarrollo cultural del español ${ }^{2}$ y se refiere a la finalidad de algunas de estas obras de acuerdo con el nuevo público al que están dirigidas, como ciertos textos médicos:

Se multiplican los doctrinales de caballería, los libros acerca de la conducta del príncipe, los tratados de halconería
y los manuales relativos al servicio de la mesa, amén de una rica tratadística religiosa. Si la mayoría de estos
textos tienen por objetivo codificar la vida de los nobles y dar brillo a sus representaciones públicas, no faltan
obras encaminadas a mejorar las condiciones de las clases populares. Algunos de los libros de medicina en lengua
castellana son una buena muestra de esta segunda tendencia. (p. 80).

En relación con esta diversidad textual, Oesterreicher (2005, p. 731) hace énfasis en la necesidad de tomar en cuenta todas las variedades que coexisten en el "espacio variacional" de una lengua para entender los usos y cambios lingüísticos generados en una época determinada 3 :

A este espacio variacional corresponde un espacio discursivo, que se define como el conjunto de tradiciones discursivas, géneros textuales o estilos que manifiestan las gradaciones del continuum concepcional entre los polos extremos de 'inmediatez' y 'distancia comunicativas', entre la oralidad y la escrituralidad. En este sentido, una Historia de la lengua ha de tener en cuenta también los materiales lingüísticos que han venido al margen de unos estudios demasiado centrados en la lengua literaria e integrar sistemáticamente los resultados de las investigaciones variacionistas y sociolingüísticas (p. 731).

Uno de los subdominios textuales de la época bajomedieval y de principios del Renacimiento en España es precisamente el de los textos de medicina escritos en lengua vernácula, el cual forma parte del dominio macro del universo de los discursos del saber 'científico', de acuerdo con Oesterreicher (2005, p. 740). Ahora, si bien este universo discursivo representa de manera general una "textualidad que corresponde perfectamente al polo extremo de la concepción escrita” (Oesterreicher, 2005, p. 744), las obras de medicina que son objeto de estudio en el presente trabajo se caracterizan por estar dirigidas a un público no necesariamente especializado en medicina, lo cual tiene sus implicaciones en la configuración textual.

Gutiérrez Rodilla (1998) señala que la elaboración de obras de medicina en romance aumenta a finales de la Edad Media y durante el siglo $\mathrm{XVI}^{4}$, aunque la traducción de textos

1 Este artículo se inscribe en el proyecto de investigación "Historia del discurso médico en español: estrategias textuales e interpersonales en la tradición médico-científica escrita” (número B7193), el cual se ejecutó en el Instituto de Investigaciones Lingüísticas de la Universidad de Costa Rica. La carga académica para realizar este proyecto fue asignada por la Escuela de Filología, Linguiística y Literatura de la Universidad de Costa Rica.

2 De acuerdo con Eberenz (2001, p. 79), "tal diversificación parece preparar el terreno para la gran difusión del libro que traerá consigo la instalación de las primeras imprentas en España a partir de 1480".

3 En el trabajo citado, Oesterreicher (2005) se concentra en el español del Siglo de Oro.

4 De acuerdo con esta investigadora, el aumento de la producción de textos de medicina en romance tiene que ver con el papel político de las lenguas vernáculas en los procesos de unificaciones nacionales (Gutiérrez Rodilla, 1998, p. 64). En relación con este incremento de textos escritos en castellano durante el siglo XV, Eberenz (2001, p. 80) agrega: "La sustitución lingüística tanto en los tratados de medicina como en los regimientos de peste es, sin duda alguna, un dato significativo. La podemos relacionar con la valorización general del castellano en cuanto lengua de cultura y, más particularmente, con el hecho 
científicos del latín al español era una práctica frecuente ya desde el siglo XIII. Además, es importante tener en cuenta que esta tendencia se extiende a todo el ámbito europeo, como afirma Taavitsainen (2006) en relación con la escritura de textos de medicina en inglés durante los siglos XIV y XV. Evidentemente, la escritura de textos médicos en lengua vernácula supone su divulgación a un público más amplio. Ahora bien, estos nuevos destinatarios definitivamente no tenían el mismo nivel de conocimiento sobre medicina. Así, Gutiérrez Rodilla (2009) acota que muchas de estas obras estaban pensadas para médicos sin una educación universitaria y que no sabían latín, como los cirujanos-barberos, los herboristas y los boticarios, por ejemplo, quienes se encargaban de desempeñar tareas más prácticas. Debido a esto, surgen diversos manuales instructivos escritos en castellano para dirigir los oficios de estos practicantes. Igualmente, en este nuevo público se encontraban personas que se interesaban por la curación y la prevención de enfermedades, por lo cual también se redactan textos de terapéutica y regímenes sanitarios en castellano. Como señala Siraisi (1990), el mundo de la medicina de entonces se extendía a practicantes que no habían recibido una formación universitaria.

Pensado Figueiras (2014, p. 45) se refiere a este tipo de textos como "obras de carácter extraacadémico", pues eran consideradas "una literatura menor, de gran pobreza científica y con elementos supersticiosos". De acuerdo con este autor, la finalidad de estas obras era simplificar asuntos esenciales de la teoría y de la praxis de la medicina para que los practicantes fueran capaces de curar. Unas obras representativas de este carácter extraacadémico son precisamente los recetarios medievales conformados por un conjunto de recetas terapéuticas, de acuerdo con Pensado Figueiras (2014). Según De la Cruz Cabanillas y Serrano Larráyoz (2017), los recetarios se caracterizan por tener una estructura simple y son textos más propensos a ser asociados con la lengua vulgar. En efecto, esto tiene que ver con el carácter eminentemente práctico de los libros de recetas. Ahora bien, las recetas médicas aparecen en otros tipos de textos médicos escritos en español durante la Baja Edad Media y comienzos del Renacimiento. Así, como observan De la Cruz Cabanillas y Serrano Larráyoz (2017), las recetas se encuentran en varios manuscritos relacionados con la medicina. Igualmente, Solomon (2010) afirma que las recetas médicas surgen en todo tipo de textos, desde las obras de terapéutica y regímenes sanitarios, hasta los tratados de carácter más erudito sobre cirugía, anatomía y patología.

Todas las recetas, ya sean médicas o culinarias, se distinguen por brindar una serie de instrucciones para preparar un tipo de medicina o alimento, como señala Marqués-Aguado (2014):

Recipes have a clear writing purpose (Taavitsainen, 2001: 86; Carroll, 2004: 187), which is that of providing instructions on how to prepare some kind of medicine, meal or utility, as Taavitsainen explains (2001: 86). Different types of recipes may be found (medical, culinary, etc.), but the instructive function prevails in all cases (QuintanaToledo, 2009: 24) (p. 108).

Es decir, en las recetas predomina una función instructiva que a su vez determina los rasgos lingüísticos de la receta como texto. Halliday y Matthiessen (2006, p. 356) definen las recetas de la siguiente manera: "A recipe is a kind of procedural text - a sequence of operations

de que el saber médico deja de ser el monopolio de la universidad. Por lo visto, no se trata de ningún conflicto de competencias, ya que son los propios profesores universitarios quienes se encargan de la divulgación de sus conocimientos. Estos textos se redactan en una época en que los historiadores han observado un descenso de la producción y de la calidad en la literatura médica peninsular". Véase también Lapesa (2008, p. 249) sobre la coincidencia de los procesos lingüísticos de unificación y expansión del castellano con las empresas nacionales en Europa. 
for arriving at some-well defined end result, such as an assembled piece of furniture, a smoothly running car, a well-kept garden or a dish". Las recetas médicas, propiamente, han sido definidas de manera amplia por Solomon (2010, p. 72): "I use the term recipe in a very broad sense to refer to a written instruction for the creation or medicinal use of individual or compound substances that have been identified as being able to alter the human body". El autor citado hace referencia a las recetas que aparecen en los tratados de medicina escritos en castellano durante la época bajomedieval e inicios del Renacimiento y señala que están concentradas en los beneficios para la salud obtenidos a través del medicamento por preparar. Eberenz (2001) también se refiere a las recetas médicas que aparecen en los regimientos de peste redactados a finales de la Edad Media en la Península Ibérica y las define como una "clase de consejo" que indica cómo preparar un medicamento. De acuerdo con el autor:

Se trata de unas secuencias con función apelativa, caracterizadas por unas marcas morfológicas y léxicas particulares. Y, como ocurre hasta hoy en día, sus elementos de contenido indispensables son la relación de los ingredientes con sus respectivas cantidades y la evocación de los actos necesarios para la elaboración del producto (p. 85).

Desde el punto de vista lingüístico e histórico, las recetas médicas han sido estudiadas sobre todo en diversos textos de medicina producidos en inglés antiguo, inglés medio e inglés moderno temprano, como en los trabajos de Sylwanowicz (2018), Bator y Sylwanowicz, (2017) y Marqués-Aguado (2014 y 2018), por citar algunos ejemplos recientes ${ }^{5}$. Como indican Bator y Sylwanowicz (2017) y Marqués-Aguado (2018), las recetas médicas han sido analizadas como género discursivo y como tipo de texto. Puesto que el enfoque de los géneros recae en cómo el texto se relaciona con el contexto extralingüístico, las recetas médicas se han caracterizado a partir de su función instructiva (Bator y Sylwanowicz, 2017). Por lo tanto, se ha prestado atención a su configuración estructural (Marqués-Aguado, 2018). En este sentido, Sylwanowicz (2018) distingue tres etapas generales en la organización del texto de las recetas: a) el título o encabezamiento, b) el procedimiento (que incluye la lista de ingredientes, la preparación y la aplicación), y c) comentarios adicionales (como frases de eficacia e información sobre el almacenamiento) ${ }^{6}$.

Desde la perspectiva del tipo de texto, los análisis han girado alrededor de las características formales y lingüísticas. Entre los rasgos que han sido señalados como prototípicos de las recetas médicas, se incluyen formas verbales en modo imperativo, cláusulas breves y paratácticas, secuencias temporales, supresión del objeto, uso de préstamos y vocabulario técnico (Bator y Sylwanowicz, 2017; Sylwanowicz, 2018). Con respecto a las recetas que se incluyen en los regimientos de peste producidos en castellano durante los siglos XV y XVI, Eberenz (2001) hace énfasis en el estilo enumerativo, en la mezcla de tiempos y modos verbales y en la ambigüedad con respecto al referente cuando se utiliza la tercera persona.

Por último, valga mencionar que las tradiciones de escritura de medicina tienen una base común grecolatina, lo cual se evidencia en las semejanzas formales y de contenido entre las recetas de finales de la Edad Media en inglés y en español, como lo demuestran De la Cruz Cabanillas y Serrano Larráyoz (2017) en su estudio contrastivo entre recetarios ingleses y españoles de los siglos XIV y XV. En efecto, los autores resaltan la importancia de la Escuela

5 Estos trabajos se basan en las primeras investigaciones sobre las recetas como tipo de texto en la historia del inglés elaborados por Carroll (1999 y 2004), Görlach (2004) y Taavitsainen (2001).

6 Alonso-Almeida (1988-1999) distingue otras etapas: ingredientes, preparación, aplicación y evaluación del tratamiento. 
de Salerno y la Escuela de Montpellier en la difusión de los conocimientos de medicina en Europa occidental, aunque señalan que los recetarios ingleses, a diferencia de los españoles, no evidencian la influencia de la tradición farmacéutica árabe de las traducciones en latín del siglo XIII (De la Cruz Cabanillas y Serrano Larráyoz, 2017).

Por nuestra parte, el objetivo del presente artículo es contribuir con el conocimiento de textos de carácter extraacadémico y textos de medicina escritos en lengua vernácula durante la época bajomedieval e inicios del Renacimiento con el fin de aportar al estudio de la historia del español a través de la diversidad de su "espacio variacional" (Oesterreicher, 2005, p. 731). Los textos escogidos pertenecen al período de la lengua llamado "español medio", en tanto que se encuentra entre el "antiguo" y el "moderno" (Eberenz, 2009; Girón Alconchel, 2005). Para lograr este objetivo, ofrecemos un análisis de la configuración textual de las recetas que se encuentran en diversos textos médicos escritos en lengua vernácula, como recetarios, regimientos de peste y tratados de medicina tanto de índole general como aquellos que giran alrededor de un tema en específico.

\section{Perspectiva de la pragmática histórica}

Este trabajo se enmarca en la pragmática histórica, la cual constituye una rama de la lingüística relacionada con la lingüística histórica y la pragmática, como su nombre lo dice. Como tal, se dedica a estudiar las estructuras y las funciones del lenguaje en contextos del pasado, así como su desarrollo a través del tiempo: "Historical pragmatics focuses on language use in past contexts and examines how meaning is made. It is an empirical branch of linguistic study, with focus on authentic language use of the past" (Taavitsainen y Fritzmaurice, 2007, p. 13). Se trata de una visión amplia de la pragmática histórica de tradición europea, como lo señalan Taavitsainen y Jucker (2010), pues se caracteriza por estudiar el lenguaje del pasado dentro de un contexto sociocomunicativo más extenso.

Según Jucker (2008), la pragmática histórica comprende cuatro niveles de análisis: el nivel de las expresiones, el de los enunciados, el de los géneros y discursos y el de los dominios discursivos. En el nivel de las expresiones, las cuales constituyen las unidades de análisis más pequeñas, se estudian elementos que tengan funciones pragmáticas como las interjecciones y las formas de tratamiento nominales y pronominales, por ejemplo. El nivel de los enunciados gira sobre todo alrededor del desarrollo de los actos de habla y la metodología empleada suele ser onomasiológica, ya que se parte de la función a la forma. Los análisis a nivel de los géneros y discursos ${ }^{7}$ suelen caracterizar los rasgos de un género específico o se concentran en describir su evolución a través del tiempo. El nivel de los dominios discursivos, por último, implica el estudio del discurso en un sentido más amplio, entendido como las prácticas discursivas que ocurren en dominios de interacción socialmente definidos, como el discurso médico, el de los deportes, el de los medios de comunicación, etcétera.

En principio, el presente estudio se ubica en el nivel de los géneros y discursos, en tanto que analizamos la configuración textual de las recetas médicas como tipo de texto y género

7 Debido a la polisemia del término 'discurso', anotamos la aclaración brindada por Jucker (2008, p. 901): "In this context, the term 'discourse' refers to a self-contained linguistic unit consisting of utterances, while the term 'genre' refers to a specific type of language, such as the language of fiction, the language of medical handbooks, or the language of personal letters". 
discursivo. No obstante, siguiendo a Taavitsainen (2006), consideramos que el lenguaje en uso se define como una serie de escogencias que están a disposición de los hablantes y de los escritores a la hora de hablar y de escribir. Por lo tanto, hay que tomar en cuenta que en la producción de textos entran en juego muchos factores, como el nivel educativo y de competencia comunicativa de los escritores y de los lectores. Todos estos elementos están sujetos al cambio y se manifiestan en la aparición de ciertos patrones lingüísticos que determinan las tradiciones de producción textual dentro de una comunidad discursiva en un momento dado. En este sentido, este trabajo se inserta en el paradigma de las Tradiciones Discursivas, pues se basa en la necesidad de tomar en cuenta la variación a nivel de las tradiciones de textos en relación con el estudio de la historia de la lengua, como afirma Kabatek (2008), y en la noción de que las tradiciones discursivas constituyen un saber cultural que regula la interacción lingüística en determinadas situaciones, pues "[...] permiten a los hablantes crear un discurso o texto de forma apropiada a la situación y realizar las relevantes tareas comunicativas con éxito”, como bien lo señala Schrott (2017, p. 26).

\section{Corpus y metodología}

En este estudio, hemos seleccionado una serie de recetas médicas provenientes de distintos textos relacionados con asuntos médicos, entre los que hay recetarios, compendios generales, tratados sobre temas específicos y regimientos de peste. Trabajamos con las ediciones ofrecidas por la Biblioteca Digital de Textos del Español Antiguo del Seminario de Estudios Medievales Hispánicos de la Universidad de Wisconsin, Madison (Gago Jover, Herrera y González de Fauve, 2015). En la Tabla 1, presentamos los textos seleccionados, la abreviatura que empleamos para reconocerlos a lo largo de este artículo y la información relativa al autor o traductor del texto ${ }^{8}$ y el lugar de producción. Los datos han sido tomados de la Biblioteca Digital de Textos del Español Antiguo:

Tabla 1. Textos de medicina empleados

\begin{tabular}{|l|c|c|c|}
\hline \multicolumn{1}{|c|}{ Texto y ediciones } & $\begin{array}{c}\text { Abreviatura } \\
\text { empleada }\end{array}$ & Autor o traductor & $\begin{array}{c}\text { Lugar de } \\
\text { producción }\end{array}$ \\
\hline $\begin{array}{l}\text { El libro de recetas (1471) } \\
\text { (Zurrón, 2012) }\end{array}$ & Lib.Rec. (1471) & $\begin{array}{c}\text { Autor: Gilberto } \\
\text { Traductor: desconocido }\end{array}$ & --- \\
\hline $\begin{array}{l}\text { Secretos de la medicina (1471) } \\
\text { (Jiménez Ríos, 2012) }\end{array}$ & Sec.Med. (1471) & Autor: Juan Enríquez & --- \\
\hline $\begin{array}{l}\text { Compendio de la humana salud } \\
\text { (1494) } \\
\text { (Herrera, 2012) }\end{array}$ & $\begin{array}{c}\text { Comp.Hum.Sal. } \\
(1494)\end{array}$ & $\begin{array}{c}\text { Autor: Johannes de } \\
\text { Ketham } \\
\text { Traductor: desconocido }\end{array}$ & Zaragoza \\
\hline $\begin{array}{l}\text { Tratado contra la pestilencia y ayre } \\
\text { corrupto (1518) } \\
\text { (Capuano, 2012) }\end{array}$ & Tr.Pest. (1518) & Autor: Alonso Espina & Valladolid \\
\hline $\begin{array}{l}\text { Libro de medecina llamado macer } \\
\text { (1527) } \\
\text { (Becker, 2012) }\end{array}$ & Lib.Mac. (1527) & $\begin{array}{c}\text { Autor: Desconocido } \\
\text { Traductor: Maestre Gil } \\
\text { de la nación castellana }\end{array}$ & Valladolid \\
\hline
\end{tabular}

8

Si bien en la Biblioteca Digital de Textos del Español Antiguo (Gago Jover et al., 2015) se atribuye la autoría del Libro de recetas a Gilberto Ánglico, Pensado Figueiras (2014) sostiene que en realidad el texto castellano es una traducción del Thesaurus pauperum de Pedro Hispano. 


\begin{tabular}{|l|c|c|c|}
\hline $\begin{array}{l}\text { Libro del arte de las comadres o } \\
\text { madrinas y del regimiento de las } \\
\text { preñadas y paridas y de los niños } \\
\left(\begin{array}{l}1541) \\
\text { (Piñeyrua, 2012) }\end{array}\right.\end{array}$ & Autor: Damián Carbón & Mallorca \\
\hline $\begin{array}{l}\text { Breve tratado de peste con sus } \\
\text { causas, señales y curación (1598) } \\
\text { (González de Fauve, 2012) }\end{array}$ & Br.Tr.Pest. (1598) & Autor: Antonio Pérez & Madrid \\
\hline
\end{tabular}

A su vez, de los textos seleccionados escogimos los pasajes con recetas médicas. Para esto, hicimos una búsqueda manual con el fin de extraer los fragmentos textuales en los que se dan instrucciones de manera explícita a los lectores para que preparen un medicamento que ha de ser administrado a un paciente. En la Tabla 2, mostramos los datos sobre el total de palabras de cada texto ${ }^{9}$, el número de recetas médicas (RMs) que hemos sacado de cada texto y el número de palabras de los pasajes de recetas médicas:

Tabla 2. Número de recetas médicas (RMs) por texto

\begin{tabular}{|l|c|c|c|}
\hline \multicolumn{1}{|c|}{ Texto } & $\begin{array}{c}\text { Núm. palabras del } \\
\text { texto }\end{array}$ & Núm. RMs en el texto & Núm. palabras RMs \\
\hline Lib.Rec. $(1471)$ & 48489 & 100 & 4795 \\
\hline Sec.Med. $(1471)$ & 8347 & 42 & 3863 \\
\hline Comp.Hum.Sal. $(1494)$ & 36110 & 140 & 9959 \\
\hline Tr.Pest. $(1518)$ & 6719 & 17 & 1581 \\
\hline Lib.Mac. $(1527)$ & 35125 & 18 & 3180 \\
\hline Lib.Com. $(1541)$ & 58681 & 217 & 12624 \\
\hline Br.Tr.Pest. $(1598)$ & 7872 & 23 & 2064 \\
\hline \multicolumn{1}{|c|}{ Total: } & $\mathbf{2 0 1 3 4 3}$ & $\mathbf{5 5 7}$ & $\mathbf{3 8 0 6 6}$ \\
\hline
\end{tabular}

El Lib.Rec. ha sido el único texto en el que no hemos realizado una búsqueda manual de pasajes con recetas, sino que tomamos las primeras 100 recetas de la obra. Eso sí, nos fijamos en que cada una de ellas indicara cómo elaborar un remedio, de modo que no sea solo la recomendación de una sustancia médica.

En cuanto a las otras obras, la selección de pasajes con recetas médicas no está libre de problemas. Puesto que no se trata de recetarios, la inserción de las instrucciones para preparar un medicamento en estos textos de medicina sigue otra lógica. En el caso del Lib. Com., por ejemplo, las recetas se incluyen de acuerdo con las enfermedades que se están discutiendo en el libro, por lo cual para tratar un solo malestar a veces se recomiendan varias recetas que no están separadas por títulos, sino por otros mecanismos, como veremos en la sección 4.3. Igualmente, a veces un preparado médico implica su uso junto con otro remedio, simultáneamente o inmediatamente después. Si para el segundo remedio se dan instrucciones, entonces consideramos cada una de ellas como una receta individual. Sirva a modo de ejemplo

9 Esta información la hemos obtenido de la Biblioteca Digital de Textos del Español Antiguo (Gago Jover et al., 2015). 
el siguiente caso del Lib.Com. (1541, fol. $\left.55 \mathrm{r}^{10}\right)$, como se muestra en la Figura 1, en el que primero se dan las instrucciones para la preparación de un perfume (1) después del cual hay que aplicar un ungüento (2), cuyas indicaciones están en latín:

Pueden hazer vn perfume y es. Tomar hojas de maluas bisimaluas hojas de violetas azules paritaria corona de rey fenu griego: de cada vno vn puño y sea cozido con agua: la qual echada dentro el bazin y la muger assentada tome el humo caliente:

\section{despues vnten le}

con este vnguento.

Recipe olei violati olei anfanaci .anna. quartum .j. vitelli

vnius oui croci gragea vj. butiri recentis dracmas .iij. misceantur \& fiat linimentum. Del qual despues dela fumentacion se vntara las almorranas.

Figura 1. Ejemplo de 2 recetas individuales en un mismo texto

Con respecto al uso del latín, es usual que en las obras de medicina se alterne entre el latín y el español. En el Lib.Com. (1541), de hecho, muchas de las recetas están escritas en latín ${ }^{11}$. Estas recetas en latín las hemos tomado en cuenta, pues algunos de sus elementos (ya sea el título, la preparación, la aplicación) están redactados en español.

En otras ocasiones, una receta puede incluir indicaciones adicionales o alternativas para la curación, pero sin que estas impliquen la preparación de un nuevo medicamento. En estos casos, consideramos que se trata de una sola receta, como ilustramos en la Figura 2 con un ejemplo del Comp.Hum.Sal. $\left(1494\right.$, fol. 27v) ${ }^{12}$ :

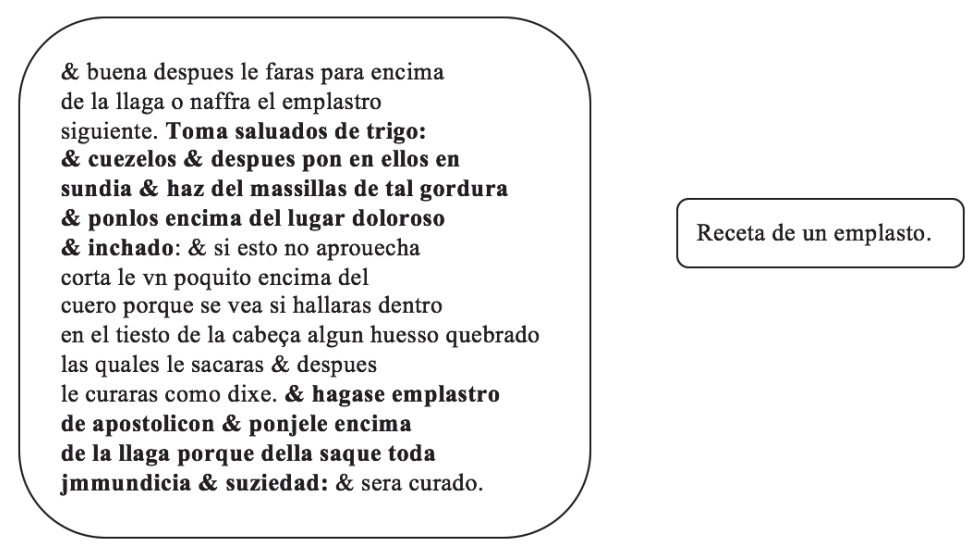

Figura 2. Ejemplo de una sola receta

10 En los pasajes textuales obtenidos de las fuentes primarias, se señala la posición del texto en el manuscrito mediante el número de folio 'fol., recto 'r' o verso ' $v$ '.

11 Véase Cruz Volio (2018).

12 Las negritas de los ejemplos son nuestras. 
En la receta presentada en la figura anterior, se dan las instrucciones para la preparación de un emplasto. Seguidamente, se recomienda la administración del llamado emplastro de apostolicon ${ }^{13}$, para el cual no se dan las indicaciones de su elaboración. Por lo tanto, no cuenta como otra receta.

Por último, si bien hemos incluido ciertos datos numéricos para ilustrar ciertos fenómenos, aclaramos que el enfoque de este trabajo es cualitativo. La información cuantitativa ha de servir solo como punto de referencia.

\section{Configuración textual de las recetas}

A continuación, analizamos la configuración textual de las recetas médicas encontradas en textos de medicina escritos en lengua vernácula durante los siglos XV y XVI.

\subsection{Estructura de las recetas}

De acuerdo con De la Cruz Cabanillas y Serrano Larráyoz (2017), quienes a su vez se basan en las investigaciones de Alonso-Almeida (1988-1999) y Taavitsainen (2001), las recetas médicas, como género discursivo, están conformadas por una serie de elementos que mantienen el siguiente orden: a) título, b) ingredientes, c) preparación, d) aplicación y e) eficacia. Según los autores citados, el título es el único elemento obligatorio, pero, como veremos en la sección 4.3, esto en realidad depende del tipo de obra médica y la forma en que las recetas están integradas en ella. Por lo tanto, hemos analizado por aparte la forma en que las recetas son incorporadas en el texto (al igual que Alonso-Almeida, 1988-1999). A continuación, presentamos el análisis de la estructura de las recetas médicas según sus ingredientes, la preparación, el modo de aplicación y los comentarios sobre su eficacia.

\subsubsection{Ingredientes}

La sección de los ingredientes se encarga de presentar el material necesario para preparar la receta (Alonso-Almeida, 1998-1999) y se incluye después del título o de las frases que incorporan la receta en el texto. Como señalan Cruz Cabanillas y Serrano Larráyoz (2017), en estos textos de medicina medievales los ingredientes forman parte del cuerpo de la receta, pues no se anotan a modo de lista. Suelen estar introducidos por el verbo tomar en segunda persona singular de imperativo ${ }^{14}$, aunque a veces se omite cualquier forma verbal, como observamos en el ejemplo 2:

1. Toma dos partes de alarguez

\& dos partes de atutia \& de açunbar

$\&$ de cardenjllo quanto $v n$

garuanço todo bien molido \&

vn grano de açucar cande $e$

vnas hebras de açafran. (Sec.Med., 1471, fol. 6r).

13 "Preparado medicinal de uso externo en forma de ungüento formado por doce elementos simples" (Lleal, 2020).

14 Marqués-Aguado (2018, p. 253) observa lo mismo en las recetas médicas en inglés: "Linguistically speaking, the imperative verb form take normally introduces ingredients, although other, more specialised verbs are sometimes used (e.g. choose), along with general verbs like put". 
2. En tiempo caliente de rosas sandalos camphora cortezas de granadas atarahe: granos de arrayan: cortezas de manc'anas: membrillos: cada uno delo que pudiere. (Tr.Pest., 1518, fol. 3v).

Los ingredientes están conformados por frases nominales compuestas por un sustantivo y por distintos modificadores, frases preposicionales y cuantificadores. Como se observa en los ejemplos anteriores, las frases nominales pueden estar unidas mediante la conjunción copulativa $e$, la cual se representa con el signo tironiano (que en las ediciones empleadas se transcribe con el símbolo \&) o bien simplemente yuxtapuestas.

Si bien hay recetas en donde se especifican las medidas exactas de los ingredientes, en la mayoría de ellas solo se mencionan los materiales que lleva la receta, como se observa en la Tabla 3:

Tabla 3. RMs que especifican medidas exactas

\begin{tabular}{|l|c|c|}
\hline \multicolumn{1}{|c|}{ Texto } & Núm.RMs & Núm.RMs con medidas exactas \\
\hline Lib.Rec. (1471) & 100 & 6 \\
\hline Sec.Med. (1471) & 42 & 8 \\
\hline Comp.Hum.Sal. (1494) & 140 & 34 \\
\hline Tr.Pest. (1518) & 17 & 9 \\
\hline Lib.Mac. (1527) & 18 & 3 \\
\hline Lib.Com. (1541) & 217 & 195 \\
\hline Br.Tr.Pest. (1598) & 23 & 12 \\
\hline Total: & $\mathbf{5 5 7}$ & $\mathbf{2 6 7}$ \\
\hline
\end{tabular}

El hecho de que el texto Lib.Com. (1541) sea el que cuenta con la mayor cantidad de recetas con medidas exactas tiene que ver con el carácter más erudito del texto, lo cual también se observa en el uso de la lengua latina a lo largo de la obra, ya sea para citar, para marcar etapas textuales o para recopilar recetas ${ }^{15}$. Aunque se supone que la obra de Carbón estaba dirigida a las parteras, en realidad se trata de una obra pensada para la comunidad de médicos de tradición erudita y formación universitaria:

Carbón's book was the first on childbirth to be published in Spain and the second in Europe after Roesslin's Rosengarten, which had been published twenty-eight years previously. Carbón and Alonso de los Ruyzes wrote their books specially for midwives, who were considered to be badly informed and, as Carbón pointed out, 'moved by charity, I will show them in this little work their art and the rules and form that [the said art] must have to be sufficient'. The fact that they were largely written in Castilian bears direct relation to their intended readership. However, such works were not only aimed at midwives. Those of Alonso de los Ruyzes and Núñez were more learned and contained numerous paragraphs in Latin, above all 'the prescriptions, remedies, precepts and grave matters', with the clear intention of being no use to the Romancistas (those who knew no Latin), including midwives (Ortiz, 1993, p. 97).

15 Véase Cruz Volio (2018) sobre las funciones del latín en textos de medicina de la misma época escritos en español. 
Al haber sido escrito por un médico instruido, de formación universitaria ${ }^{16}$, es más probable que dominara los sistemas métricos usuales en el mundo de la medicina. De acuerdo con Alonso-Almeida (1998-1999), en las recetas que no se especifican las medidas, el destinatario debe interpretar la cantidad de los ingredientes de acuerdo con su propio conocimiento, lo cual se relaciona también con el carácter de tradición oral de las recetas. En este punto, es necesario recordar el bajo nivel de alfabetización de la época, que no alcanzaba ni el $20 \%$ (Gallego-Caminero et al., 2005), por lo cual en realidad los textos podían ser leídos por muy pocas personas, como afirma Solomon (2010).

La precisión de la cantidad de los ingredientes puede estar dada tanto por numerales (tres rayzes con sus fojas de plantayna, Comp.Hum.Sal., 1494, fol. 18v) como por unidades de medida de acuerdo con distintos sistemas métricos usados en la época ${ }^{17}$. Por supuesto, estos serían los términos más específicos (Bator, 2017), como por ejemplo dracma, escrúpulo, libra y onza, entre otros. Además, se emplean otros términos cuya cantidad específica está dada por el tipo de contenedor (Bator y Sylwanowicz, 2017), como cuchara. Igualmente, también su usan términos de carácter general, como manada y manojo, entre otros ${ }^{18}$. En otros casos no se especifica la medida, sino que solo se indica que los ingredientes de la receta en cuestión deben usarse en la misma proporción (ejemplo 3). La indicación de la medida suele anteceder al ingrediente al que se refiere, pero la cantidad necesaria también puede especificarse después de los ingredientes (ejemplo 4).

3. iten peregil picalo bien \& toma sangre

de puerco \& mesclalo todo con

vino blanco tanto de vno commo

de otro (Lib.Rec., 1471, fol. 3r).

4. vngento dialtea

sinple: sayno de puerco \& de gallina

\& de anade: \& vngento marciaton

\& olio nardino: de cada vno .onza. media. (Comp.Hum.Sal., 1494, fol. 39v).

16 De acuerdo con Gallego-Caminero et al. (2005, p. 604), el médico Damián Carbón “Obtuvo el título en Artes y Medicina en Valencia. Fue nombrado Médico Ordinario de Sanidad o Morbería del Reino y de las Islas Baleares y en 1520 se le titula, según la documentación de la época, "in medicina doctor", al parecer en fecha anterior a la de alcanzar el doctorado que se supone obtuvo en 1528 ". Según De la Cruz Cabanillas y Serrano Larráyoz (2017), en Castilla eran conocidos los sistemas de tradición griega y romana, pero las mismas unidades tenían distintas equivalencias según los territorios en donde se emplearan.

18 Anotamos las definiciones del DiCCA XV - Diccionario del castellano del siglo XV en la Corona de Aragón dirigido por Lleal (2020):

dracma: "Unidad de medida de peso utilizada en farmacia, equivalente a un octavo de onza, a tres escrúpulos o a 3'59 gramos."

escrúpulo: "Unidad de medida de peso usada en farmacia, equivalente a dos óbolos, 24 granos o 1,2 gramos)."

libra: "Unidad de medida de peso equivalente generalmente a 12 onzas (aproximadamente 400 gramos)." onza: "Unidad de medida de peso equivalente a 16 arienzos (aproximadamente a 29,2 gramos)."

cuchara: "unidad de medida de peso utilizada en farmacia, equivalente a un octavo de onza, a tres escrúpulos o a 3'59 gramos."

manada: "Conjunto de vegetales o de otras cosas alargadas, atadas o asidas por su centro". manojo: "Gran cantidad de cosas." 
Los ingredientes pueden estar acompañados de modificadores como adjetivos (toma lagartuxas verdes bibas, Lib.Rec., 1471, 3r) o de participios que indican que el ingrediente ha sido procesado de alguna manera (hermodatiles mondados dentro y de fuera, Lib.Mac., 1527, en donde 'mondados' quiere decir que han sido limpiados). Además, en las listas de ingredientes se recurre al empleo de aclaraciones terminológicas o 'glosas', como las denomina Hyland (2007), que sirven para explicarle al lector de qué ingrediente se está hablando:

5. Tomaran hojas de lauamanos que se dize lauendula (Lib.Com., 1541, fol. 55r).

6. toma la barbajouis que se dize tapsus barbatus (Comp.Hum.Sal., 1494, fol. 33r).

7. toma

las cantarides que son vnos gusanillos verdes redondos que reluzen de noche (Comp.Hum.Sal., 1494, fol. 36r).

Estas aclaraciones terminológicas vienen introducidas por frases como que se dice o que (se) llama. Como vemos en los ejemplos 5 y 6, estas glosas sirven para hacer una oposición entre dos términos, uno en castellano (lauamanos) o de uso común (barbajouis, tomado del latín barba Jovis 'barba de Júpiter' (Lleal, 2020) y otro en latín (lauendula y tapsus barbatus). En el ejemplo 7, por otro lado, el término considerado como menos conocido, por su carácter científico, cantarides (del latín cantharidem 'escarabajo', y este, a su vez, del griego kantharos ${ }^{19}$ ), se aclara mediante una descripción más detallada. De igual manera, se evidencia una preocupación por que el lector no profesional entienda los conceptos. Si bien este tipo de aclaraciones se da en todos los textos, en los que más encontramos ejemplos así son el Comp. Hum.Sal. (15 instancias) y el Lib.Com. (8 instancias) ${ }^{20}$.

\subsubsection{Preparación}

Después de que se enumeran los materiales necesarios para la elaboración del remedio, siguen las indicaciones para su preparación. Si bien mencionamos por aparte esta etapa, es importante aclarar que, en cuanto a la organización textual, las instrucciones sobre la preparación y la administración del remedio no están separadas de los ingredientes, como suele suceder en la composición de las recetas contemporáneas, en donde aparecen como dos secciones distintas. En la Figura 3 ponemos un ejemplo del Sec.Med. (1471, fol. 2v-2r) con las etapas de una receta:

19 En el DiCCA-XV (Lleal, 2020), se registran las siguientes variantes formales: cantarida, cantaridet, cantorida y cantoridas. De acuerdo con este diccionario, se define como un "Insecto coleóptero de color verde, de cuyas alas se extrae una sustancia usada en medicina (lytta vesicatoria)".

20 Nos referimos solo a los pasajes de recetas médicas, pues la definición de términos era una práctica habitual de estos textos en lengua vernácula. Para esto, véase Cruz Volio (en prensa). 


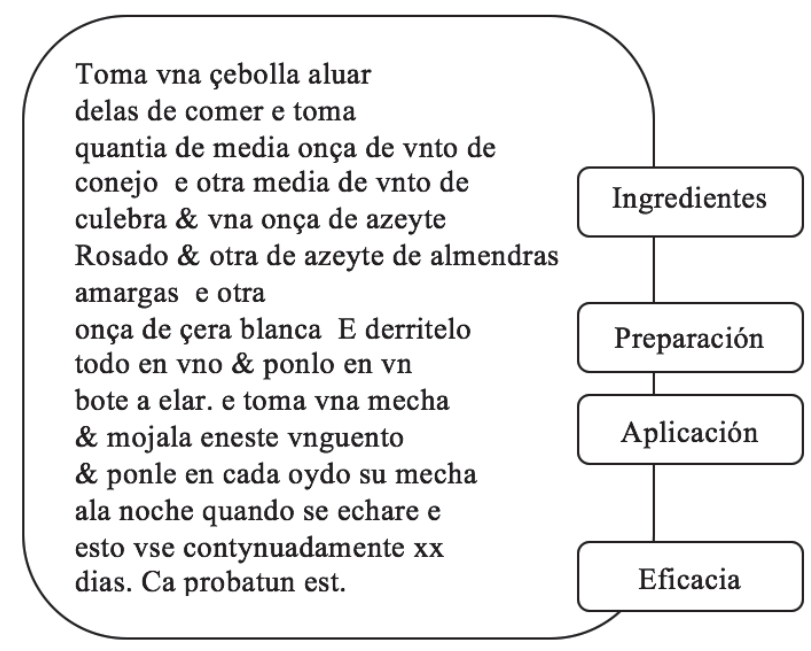

Figura 3. Etapas de una receta

En los textos analizados, reconocemos la etapa de la preparación por la presencia de verbos relacionados con procedimientos, especialmente culinarios, que hay que aplicar a los ingredientes. Si bien se emplean procedimientos culinarios que requieren el uso del fuego ${ }^{21}$, como hervir, quemar, cocer, las recetas médicas tienden a dar instrucciones que implican la manipulación de los ingredientes por medio de otros procedimientos como echar, picar, mezclar y colar. Además, en la fase de la preparación también se usan verbos más especializados como amasar, batir, moler, mondar, rallar, majar, revolver, exprimir, entre otros:

8. E faz dos panes dela

dicha masa \& cuezelos en forno

mucho calyente \& pone enel

suelo de cada pan. vn suelo

muy delgado de otra masa por

que no se pegue al forrno e

despues faz vn formigo enesta

manera Ralla vn poco del vn

pan \& echa las Ralladuras en

vna ollilla nueua \& echa por

caldo leche de avellanas \& vn

poco de culantro seco molido

(Sec.Med., 1471, fol. 13r).

Puesto que las recetas médicas muchas veces dan instrucciones para la preparación de alimentos, cuesta distinguirlas de las recetas propiamente culinarias, pues ambos son géneros determinados por su carácter instructivo. En efecto, en las recetas médicas se usan verbos que indican "actos culinarios", como designa Eberenz (2016, p. 84) a los lexemas que

21 Eberenz (2016) realiza un análisis diacrónico de los lexemas que se refieren a procesos culinarios en español. 
hacen referencia a una noción general relativa a la elaboración de comida. No obstante, por lo menos en las recetas médicas analizadas en este estudio, no contamos con verbos referentes a técnicas de conservación de alimentos, como freír y adobar (este segundo con el sentido de cómo 'sazonar [un alimento] con sal, hierbas con sal, hierbas aromáticas y / o especias, etc.', de acuerdo con Eberenz [2016, p. 88]). De igual manera, tampoco encontramos verbos culinarios con un sentido más técnico como ahogar, perdigar y sancochar, entre otros, que son analizados por Eberenz (2016).

Como observamos en el ejemplo 9, la secuencia de las instrucciones se realiza por medio de la conjunción copulativa $e$ (representada con el signo tironiano y transcrita con el símbolo \&):

9. iten toma los brotos \& las fojas de la figuera amarga \& picalos mucho et destienplalos con açeite \& con fuerte vinagre \& annade çenjza de çepa de col çenjza de las casas de las cabeças de los ajos \& escoria de plata molida \& argenbibo \& çefura \& çenjza de xabon \& picalo todo mucho \& a manera de vnguento \& rraydos los pelos laua la cabeça con fuerte vjnagre o con orines \& vnta con el dicho vnguento muchas de vegadas \& sanaras. espirençi. (Lib.Rec., 1471, fol. 4r).

Aparte del estilo paratáctico, la información relativa a la preparación de la sustancia médica puede ser bastante vaga e imprecisa. Esto sucede sobre todo en las recetas prototípicas, es decir, las que se encuentran en los recetarios como el del ejemplo 9. En otros tipos de textos, como los regimientos de peste, cuya finalidad se acerca más a la de brindar consejos y recomendaciones, así como en otros tratados de medicina, más bien hay instancias en donde las indicaciones son muy detalladas.

\subsubsection{Aplicación}

Después de la preparación de la receta, sigue la aplicación del medicamento, aunque esta etapa textual a veces se confunde con la anterior. En esta sección de la receta médica, se dan instrucciones relativas al modo de empleo del medicamento preparado, información sobre la dosificación, la frecuencia y la duración del tratamiento. En cuanto al modo de empleo, los detalles se refieren a cómo hay que aplicar el medicamento, por lo cual a menudo se mencionan partes del cuerpo (véase también Marqués-Aguado, 2018):

10. \& pon ençima dela boca dela olla vn cuello de calabaça foradado e aquel perfume que saliere por el cuello dela calabaça Resçibalo el paçiente por las narizes. (Sec. Med., 1471, fol. 2v).

Puesto que estos textos de medicina estaban pensados ya sea para la curación personal o bien para tratar a otras personas, es usual que en la sección de la aplicación del medicamento se dé información sobre la duración del tratamiento. De hecho, esto ocurre en todos los textos, excepto en el Tr.Pest. (1518). La duración de la aplicación del tratamiento se da en términos de la cantidad de días o de noches en que se ha de administrar el medicamento hasta que el paciente esté sano:

11. \& haz emplasto y pon lo enla quebradura: \& sea renouado de diez en diez

dias hasta treynta dias: \& sera sano el paciente. (Lib.Mac., 1527, fol. 63v). 
La dosificación del medicamento no suele detallarse en las recetas médicas que hemos analizado, a excepción del Lib.Com. (1541), en el cual hemos contado 14 instancias que especifican la dosis con medidas exactas. En las demás obras, la información sobre la cantidad de medicina que hay que tomar tiende a ser imprecisa. En el ejemplo 12, del Lib.Com. (1541) damos un ejemplo de una receta que indica la dosis exacta de medicina:

12. Sea todo poluorizado y mezclado: y desto le daran media cucharada de plata con vn trago de vino tinto. (Lib.Com., 1541, fol. 18v).

Algunas recetas presentan información con respecto a ciertas características del paciente, como el sexo, la edad o la clase social:

\section{La quantidad para vna toma de quinze años arriba peso de vna} quarta: enlos de menor hedad la meytad pueden tomar: beuan tras ello dos o tres onc'as delas aguas sobredichas o vino. (Tr.Pest. 1518, fol. 7r).

En el ejemplo anterior, vemos cómo se distingue la cantidad de medicamento que pueden ingerir los pacientes de acuerdo con su edad.

\subsubsection{Eficacia}

Un elemento que caracteriza las recetas de todos los textos médicos analizados, en mayor o menor medida, es la inclusión de comentarios y promesas acerca de la eficacia del remedio recomendado. A este tipo de enunciados, Mäkinen (2011) las llama "frases de eficacia" y las describe de la siguiente manera:

Efficacy phrases (EPs) are passages in medical recipes that testify to the value or effectiveness of the end product: the medicine itself. The term efficacy statement was first used by Hunt in 1990. Such passages are usually dispensable: the ultimate function of a recipe is not altered by leaving the phrase out (C. Jones 1998: 199) (p. 158).

A partir de la clasificación realizada por el autor citado (Mäkinen, 2011), analizamos las frases de eficacia encontradas en los textos de medicina según se traten de frases fijas, frases específicas y frases generales. Además, hemos agregado una cuarta clase para agrupar la combinación de estas frases en una misma receta. La Tabla 4 muestra la distribución de las frases en los textos analizados:

Tabla 4. Distribución de frases de eficacia

\begin{tabular}{|l|c|c|c|c|}
\hline \multicolumn{1}{|c|}{ Texto } & Frases fijas & Frases específicas & Frases generales & Frases combinadas \\
\hline Lib.Rec. $(1471)$ & 30 & 37 & 1 & 18 \\
\hline Sec.Med. $(1471)$ & 11 & 23 & 6 & 8 \\
\hline Comp.Hum.Sal. $(1494)$ & 10 & 28 & 33 & 2 \\
\hline Tr.Pest. $(1518)$ & 0 & 1 & 6 & 0 \\
\hline Lib.Mac. $(1527)$ & 0 & 0 & 19 & 0 \\
\hline Lib.Com. $(1541)$ & 1 & 1 & 19 & 0 \\
\hline Br.Tr.Pest. (1598) & 1 & 1 & 1 & 0 \\
\hline Total: & $\mathbf{5 3}$ & $\mathbf{9 1}$ & $\mathbf{8 5}$ & $\mathbf{2 8}$ \\
\hline
\end{tabular}

Las frases de eficacia fijas son derivadas de la frase latina probatum est, en cuyo caso se enuncian en latín o se traducen como cosa prouada o es muy prouado (ambos ejemplos 
del Comp.Hum.Sal. [1494]). Asimismo, dentro de esta categoría aparecen frases verbales en presente o en futuro de indicativo con el verbo sanar, ya sea en segunda persona singular o en tercera persona singular, aunque las formas que predominan se codifican en futuro y tercera persona singular, tanto en voz pasiva como en voz activa (ejemplo 14 y ejemplo 15). Esta forma verbal es tomada de la fórmula latina sanabitur, la cual en un caso del Sec.Med. (1471) se encuentra en latín (\& continualo e sanabitur por quantia de dos meses Sec.Med., [1471, fol. 14r]), aunque tiende a aparecer en español.

14. Resçiba el enfermo por la boca

\& por las narizes estando en

su lecho muy bien cubierto. E

asy tome este fumo fasta que

sude Por çierto dize galieno

que sanara sy muchas vezes

\& a menudo asy lo faze. (Sec.Med., 1471, fol. 10v).

15. \& despues

tomaras la tercera parte de lo que alli

ternas cozido \& mezclalo con azeyte

\& bresca de miel \& en dos o tres vezes

sera sano. (Comp.Hum.Sal., 1494, fol. 29v).

En el Lib.Rec. (1471), a diferencia de los ejemplos anteriores, se menciona la palabra espirençia al final de las recetas para indicar que es eficaz, puesto que ya ha sido probada. Por esta posición, este tipo de frases también sirve para marcar el final de cada receta. En el siguiente ejemplo, el término espirençia se usa combinado con la frase fija \& sanaras:

16. \& rraydos los

pelos laua la cabeça con fuerte

vjnagre o con orines \& vnta con

el dicho vnguento muchas de vegadas

\& sanaras. espirençia

(Lib.Rec., 1471, fol. 4r).

Las frases específicas, por su parte, siempre hacen referencia a algún aspecto de la enfermedad o malestar por tratar, por lo cual son más extensas que las frases fijas:

17. \& purgara las Renes

\& la vexiga \& faz bien mear

\& estaña la sangre dela muger

\& quita el dolor delas piernas

e sy es metida enla natura

dela muger estanca la

sangre luuja. (Sec.Med., 1471, fol. 12v) $)^{22}$.

22 Valga indicar que esta misma receta aparece en el herbario llamado Macer Floridus, un texto del siglo $\mathrm{XV}$ que traduce un original latino. 
En las frases generales, de naturaleza muy variada, los escritores hacen énfasis sobre beneficios del medicamento con respecto a la salud del paciente o sobre las virtudes del preparado médico en cuanto a su durabilidad o a la rapidez del alivio que brindará:

18. \& con aquellos dos mezclados

vntate los pies o manos donde

houires la sarna \& fregalos bien con

el \& curaras ligeramente. (Comp.Hum.Sal., 1494, fol. 33v).

En ocasiones, la receta simplemente concluye con una frase que hace referencia a la obtención de una medicina descrita como maravillosa o provechosa o un medicamento superior a todos, pues las exageraciones no son raras. Otras veces, se procede a enumerar una serie de virtudes del preparado, como en el siguiente ejemplo referente a una medicina cuyas instrucciones ya se habían dado:

19. E primeramente este conforta mucho el coraçon:

\& da fortaleza alos miembros enflaquescidos:

\& cura alos que tiemblan la cabeça y las manos

E quita las manzillas dela cara: \& conserua ala persona que

se vntare el rostro en su juuentud. [...] (Lib.Mac., 1527, fol. 59r).

Evidentemente, estas promesas de eficacia cumplen una función argumentativa, pues se trata de convencer a los receptores del texto, ya sea en calidad de pacientes o de curanderos, de que la medicina en cuestión es efectiva. Con respecto a la distribución de estas frases en los textos, observamos que son más frecuentes en recetarios, como el Lib.Rec. (1471), y en otras obras médicas que contienen secciones de recetas, como el Comp.Hum.Sal. (1494), que en otros tipos de textos de medicina.

\subsection{Rasgos lingüísticos}

En las recetas médicas encontramos determinados elementos lingüísticos recurrentes, como el modo imperativo, la voz pasiva, verbos causativos, construcciones de relativo y cláusulas temporales (Alonso-Almeida, 1998-1999). En este trabajo, nos concentramos en el uso de formas verbales en las recetas médicas.

De acuerdo con Eberenz (2001), los regimientos de peste de fines de la Edad Media, los cuales también contienen pasajes de recetas, se caracterizan por el uso de determinados tiempos y modos verbales: "En nuestros textos se dan el imperativo, el presente de subjuntivo con función imperativa y, más raramente, el futuro de indicativo o, simplemente, el infinitivo" (pp. 86-87). En la Tabla 5, presentamos la distribución de las formas verbales que hemos encontrado en las recetas de los textos empleados en este estudio. Con respecto al futuro, no hemos tomado en cuenta las formas verbales de las frases de eficacia vistas en la sección anterior. 
Tabla 5. Formas verbales en las RMs

\begin{tabular}{|l|c|c|c|c|c|}
\hline \multicolumn{1}{|c|}{ Texto } & Imperativo & $\begin{array}{c}\text { Presente de } \\
\text { subjuntivo }\end{array}$ & $\begin{array}{c}\text { Futuro de } \\
\text { indicativo }\end{array}$ & Infinitivo & $\begin{array}{c}\text { Perífrasis } \\
\text { léxicas }\end{array}$ \\
\hline Lib.Rec. (1471) & 333 & 34 & 0 & 1 & 0 \\
\hline Sec.Med.(1471) & 102 & 54 & 4 & 0 & 0 \\
\hline Comp.Hum.Sal. (1494) & 434 & 63 & 50 & 10 & 2 \\
\hline Tr.Pest. (1518) & 0 & 16 & 0 & 12 & 4 \\
\hline Lib.Mac. (1527) & 9 & 36 & 4 & 3 & 18 \\
\hline Lib.Com. (1541) & 5 & 137 & 103 & 17 & 60 \\
\hline Br.Tr.Pest. (1598) & 1 & 12 & 2 & 29 & 1 \\
\hline \multicolumn{1}{|c|}{ Total: } & $\mathbf{8 8 4}$ & $\mathbf{3 5 2}$ & $\mathbf{1 7 5}$ & $\mathbf{6 0}$ & $\mathbf{8 5}$ \\
\hline
\end{tabular}

Eberenz (2001) afirma que los tiempos y modos verbales alternan de manera más o menos libre en los textos que él ha estudiado, lo cual también sucede en las recetas médicas que son nuestro objeto de estudio. No obstante, podemos señalar algunas tendencias.

Como ya se ha mencionado, el imperativo en segunda persona singular es la forma verbal prototípica de las recetas (Alonso-Almeida, 1998-1999; Marqués-Aguado, 2014). Consecuentemente, es la forma principal en los textos que compilan recetas, como el Lib. Rec. (1471), y aquellos que tienen secciones dedicadas a la recolección de recetas, como el Sec.Med. (1471) y el Comp.Hum.Sal. (1494). Aparte de emplearse con verbos relacionados con procedimientos culinarios en la etapa de la preparación de la receta, el verbo tomar es el que más se usa en imperativo de segunda persona singular (toma) para introducir los ingredientes necesarios.

El presente de subjuntivo se utiliza en tercera persona singular o plural, como ya ha sido señalado por Eberenz (2001). Además, se usa tanto en voz activa como en voz pasiva, sobre todo en la fase de preparación de la receta (aunque hay pocas instancias de la forma tomen para introducir ingredientes). En todo caso, observamos que el subjuntivo es la forma verbal empleada cuando la receta ha sido tomada de otra fuente:

\section{Para esta enfermedad}

manda giraldo que sea tomada

el estiercol blanco del perro

\& sea fecho poluos \& sea

echado sobre vn paño \& el

paño sea vntado con mjel \& con

sayn e que sea Retido ante

e despues este paño caliente

sea puesto sobre los pechos

del enfermo \& sanara. (Sec.Med., 1471, fol. 10v).

Aunque en el ejemplo anterior se menciona la fuente de la que es tomada la receta (manda giraldo), es más usual que esta no quede explícita. No obstante, igual consideramos que estos subjuntivos son casos de intertextualidad, especialmente cuando aparecen en voz pasiva, ya que son tomados de los modelos latinos de recetas: sean cochos-coquantur; sea colado-coletur; sean mezclados-misceantur, que son formas que alternan en el Lib.Com. 
(1541), en donde las recetas suelen estar en latín o en latín y en español. Cuando hay cambios de código entre estas dos lenguas, los ingredientes y la preparación se pone en latín, mientras que la aplicación del remedio va en castellano:

21. hagan le fregar los pies y den le deste xarabe.

Recipe sirupide agresta \& minue citoniorum anna dracmas .ij. misceantur. Del qual le puedan dar en ayunas tres cucharadas de plata: (Lib.Com., 1541, fol. 17r).

El Lib.Com. es el texto que presenta más formas de futuro, especialmente en tercera persona cuando se dan las instrucciones sobre la administración del preparado médico al paciente:

22. Y si esto fuere por causa de algun malhumor sera necessario hazer lo benigno y digirir lo con estos xarabes. Tomad miel rosado colado .iij. xarabe de ligua de buey. dracma .j. agua de lengua de buey y de cabiosa: de cada vna dracmas .iij. sea mezclados: del qual le daran tres mañanas continuas y assi sera partida. Despues le daran dracma .j. de mañana y dracma .j. de miel rosado: todo destemplado con agua de lengua de buey y dar lo han vna hora antes del dia y tardar le han al comer por tiempo de cinco horas. (Lib.Com., 1541, fol. 16r).

En el Comp.Hum.Sal. (1494), en donde también hay instancias de futuro, este tiempo verbal se usa para introducir recetas:

23. Para las llagas que se fazen en los pies quasi incurables: \& tienen agujeros profundos faras el azeyte que se sigue para curarla (Lib.Com., 1541, fol. 28v).

$\mathrm{El}$ infinitivo y las perífrasis léxicas son formas verbales que se emplean en textos que contienen sobre todo consejos y recomendaciones, como los tratados de peste, como vemos en el siguiente ejemplo con el uso de infinitivos en una receta incluida dentro de la obra Tr.Pest. (1518):

24. Poner sobre la nacida cosas que atrayan para fuera \& en parte resueluan como el azeyte de lilio eneldo \& de manc'anilla puesto caliente con lana sugosa tres vezes al dia renouando la lana.

Emplastro hecho de harina de ceuada: \& de linac'a: altramuces. garuanc'os negros: flor de manc'anilla: higos passos: estiercol de palomas: sea molido \& tomar la quantidad que fuere menester \& encorporado con enxundia de puerco \& todo majado \& muy mesclado \& juntar conello delos sobredichos azeytes lo que bastare \& poner dello sobre las nascidas estendido sobre venda de lino \& renouarlo dos o tres vezes al dia. (Tr.Pest., 1518, fol. 9v).

Igualmente, las perífrasis léxicas con el verbo deber se usan en el Lib.Mac. (1527) en una construcción impersonal con hombre (deue (el) hombre) para dar consejos. En el Lib. Com. (1541), libro destinado a dirigir la práctica de las parteras, se trata de perífrasis léxicas con poder: 
25. Y si por ventura no pudiere

dormir vnten le la frente de aqueste vnguento.

Recipe vnguenti rosati sandalini dracma media vnguenti

pupuleonis dracma .j. misceantur. Y estas cosas se pueden reyterar

si fuere menester. (Lib.Com., 1541, fol. 27v).

El uso de estas perífrasis con el verbo poder tiene la finalidad de brindarle al lector más opciones ya sea para preparar un medicamento, para aplicarlo o para curar a un paciente. Esto refleja el carácter menos instructivo del texto, en el sentido de que no está pensado para la curación rápida o inmediata y que no se trata de una serie de recetas aisladas que los lectores pueden consultar individualmente. Por el contrario, el Lib.Com. (1541) está organizado temáticamente de acuerdo con las afecciones y necesidades relacionadas con la concepción, la maternidad y la crianza. Además, dado el carácter erudito de la obra, como lo constatan GallegoCaminero et al. (2005) y Ortiz (1993), es evidente que su autor, el médico instruido Damián Carbón, quiere ser exhaustivo en cuanto a la presentación del conocimiento a su disposición.

\subsection{Incorporación de las recetas en el texto}

Las recetas son incorporadas en los textos mediante diversos mecanismos. En las obras que versan sobre distintos asuntos médicos, como enfermedades y partes del cuerpo, las recetas se reconocen por el uso de frases preposicionales con para o contra y el nombre del malestar, afección o parte del cuerpo que se quiere $\operatorname{tratar}^{23}$ :

\section{Para el dolor delos ojos}

\& dela axaqueca \& otras cosas (Sec.Med., 1471, fol. 13r).

\section{Contra la inchazon de las} venas despues de la sangria

Recipe (Comp.Hum.Sal., 1494, fol. 12r).

Después de estos encabezamientos, sigue la receta con las indicaciones para preparar el medicamento. El uso de estas frases se da sobre todo en los textos citados en los ejemplos anteriores. En el Comp.Hum.Sal. (1494), después de la frase preposicional correspondiente, es usual que se inserte el latinismo recipe antes de la receta propiamente, como observamos en el ejemplo 27. Eberenz (2001) observa lo mismo en las recetas incluidas en regimientos de peste. Además, el Comp.Hum.Sal. (1494) comprende una sección entera dedicada a la enumeración de enfermedades en orden alfabético, en donde después de algunas de ellas se incluye una receta que es introducida con el término cura:

28. Amissio rationis: quiere dezir frenesia:

es defallescimiento de seso \& de

razon. Cura. toma açafran \& la vrina

propia del doliente mesclado: \& de

mañana beua dello: \& sera curado (Comp.Hum.Sal., 1494, fol. 36v).

23 De la Cruz Cabanillas y Serrano Larráyoz (2017) observan que las construcciones que empiezan con contra en el título no son frecuentes en inglés, en comparación con el español de las recetas de la misma época. 
El uso de frases preposicionales también surge en el Lib.Rec. (1471), pero como esta obra es un recetario, es común que cada receta nueva sea precedida por el conector en latín iten (variante formal de item 'asimismo'). En otras obras de medicina que no son recetarios propiamente pero que tienen secciones de recetas, como el Lib.Mac. (1527), las distintas recetas que involucran el uso del romero son introducidas simplemente por el subtítulo otra recepta:

\section{Otra recepta.}

TOma el astil del romero \& quemalo hasta que se haga carbones: (Lib.Mac., 1527, fol. 61v).

Otro mecanismo consiste en incorporar las recetas por medio de nombres muy generales que hacen referencia a sustancias médicas, como medicina (o melezina) y remedio, que se utilizan para tratar enfermedades. También se recurre a la designación del tipo de medicamento que se va a preparar por medio de términos específicos. Estos nombres pueden hacer referencia a los siguientes aspectos ${ }^{24}$ :

a) Modo de aplicación del medicamento: como ungüento (que se unta), pesario (que se introduce), fumentacion (que se aplica caliente por medio de la fricción) ${ }^{25}$, gragea o dragea (que se chupa), emplastro (que se aplica con una tela sobre el cuerpo), ceroto (igual que el emplastro, pero "algo más blando" [Lleal, 2020]), brebaje (que se bebe), perfume (cuyo vapor aromático se absorbe) ${ }^{26}$.

b) Composición del medicamento: como polvos ("sustancia comestible o medicinal, molida en partículas diminutas" [Lleal, 2020]), aguas (sustancia medicinal líquida), conserva (alimento preparado para que tenga una larga duración), melicrato (jarabe a base de hierbas y raíces mezclaras con miel espumada [Lleal, 2020]), xarope (variante formal de jarope, que a su vez es una variante léxica de jarabe, "bebida preparada por decocción de agua con azúcar y alguna hierba aromática hasta que adquiera cierta consistencia" [Lleal, 2020]), confeccion (o confection), "sustancia alimenticia o medicinal compuesta de varios ingredientes" [Lleal, 2020]).

c) Finalidad del medicamento: como gargarismo (para enjuagar la garganta), purga (para evacuar los intestinos).

Si bien a veces solo se menciona una propiedad del medicamento (unguento blanco), es usual que se detalle el propósito del remedio con una frase preposicional, como ilustramos por medio del ejemplo 30. Además, en concordancia con el principio detrás de las frases de eficacia analizadas en la sección 4.1.4, en otras obras el nombre del medicamento puede ser calificado por medio de adjetivos e intensificadores que resaltan su efectividad, como ilustramos en los ejemplos 31 y 32 con el uso de la misma frase muy maraujllosa y la indicación de la utilidad

24 Sylwanowicz (2018) clasifica la denominación de preparados médicos en: a) términos generales que denotan medicamentos, b) términos que denotan la dosificación o el modo de aplicación y c) términos que denotan preparaciones específicas para tratar un malestar o una parte del cuerpo en particular. En el Diccionario de Autoridades - Tomo III de la Real Academia Española (1732), el término 'fomentación' se define de la siguiente manera: "Untúra, o fricación que se hace para dar calor al cuerpo" (Real Academia Española, 1726-1739). el mismo humo o olor que arrojan de sí las materias olorosas” (Real Academia Española, 1726-1739). 
de las recetas (De la Cruz Cabanillas y Serrano Larráyoz (2017, p. 11) también hacen esta observación sobre la incorporación de la eficacia del remedio en el título):

30. Unguento para la llaga o mal que se llama lobo. (Comp.Hum.Sal., 1494, fol. 33r).

31. Agua muy maraujllosa para tirar las manzillas \& confortar \& aguzar la vista toma finojo \& rruda \& berbena \& eufrasia endiuja çelidonja tormentilla bretonjca. (Lib.Rec., 1471, fol. 10v-11r).

\section{Muy marauillosa recepta delas virtudes del}

romero: en especial dela flor del qual se ha de hazer azeyte: conel qual obraras \& curaras infinitas passiones de enfermedades. (Lib.Mac., 1527, fol. 59r).

En obras en las que no hay secciones de recetas, sino que están intercaladas a lo largo del texto, los autores adoptan un estilo algo más personal en el sentido de que se dirigen a los lectores. Por ejemplo, el Lib.Com. (1541) presenta extensos pasajes de recetas, pero estos no son una serie de recetas desvinculadas unas de otras, como sucede en el Lib.Rec. (1471), que es un recetario, sino que el autor del Lib.Com. (1541), el médico Damián Carbón, da las recetas que él considera pertinentes para tratar la enfermedad o malestares que son el tema de los capítulos de su obra. Así, los remedios son introducidos en el texto como una indicación más que ha de seguir la persona encargada de la curación, como en el ejemplo 33, en donde la receta del xarabe le sigue inmediatamente y se señala con el término latino recipe. Igualmente, cuando un remedio le sigue a otro, como en el ejemplo 34, la receta se inserta en el texto por medio de una indicación en donde se menciona el tipo de medicamento:

33. hagan le fregar los pies y den le deste xarabe.

Recipe sirupide agresta \& minue citoniorum anna dracmas .ij. misceantur (Lib.Com., 1541, fol. 17r).

34. Despues hagan le este perfume.

Tomen alchena y pongan la sobre brassas de fuego y con vn embudo tome el humo por baxo: esperimento

den le el estomago

ayuno a comer el que se sigue

Recipe diacodionis zucaris rosati .anna dracmas .iiij. misceantur \& fiat conditum. (Lib.Com., 1541, fol. 94r).

Este estilo más personalizado hace que las recetas parezcan más bien consejos y recomendaciones, por lo cual también lo encontramos en los regimientos de peste, los cuales se caracterizan por esta función apelativa, de acuerdo con Eberenz (2001). Ilustramos este punto con una receta incluida en el Tr.Pest. (1518, fol. $7 \mathrm{r}$ ), en donde el autor sugiere un medicamento, la conserua bolarmenico (un tipo de arcilla), como alternativa de otro que había recetado anteriormente. Presentamos el ejemplo en Figura 4 para señalar las etapas de la receta: 


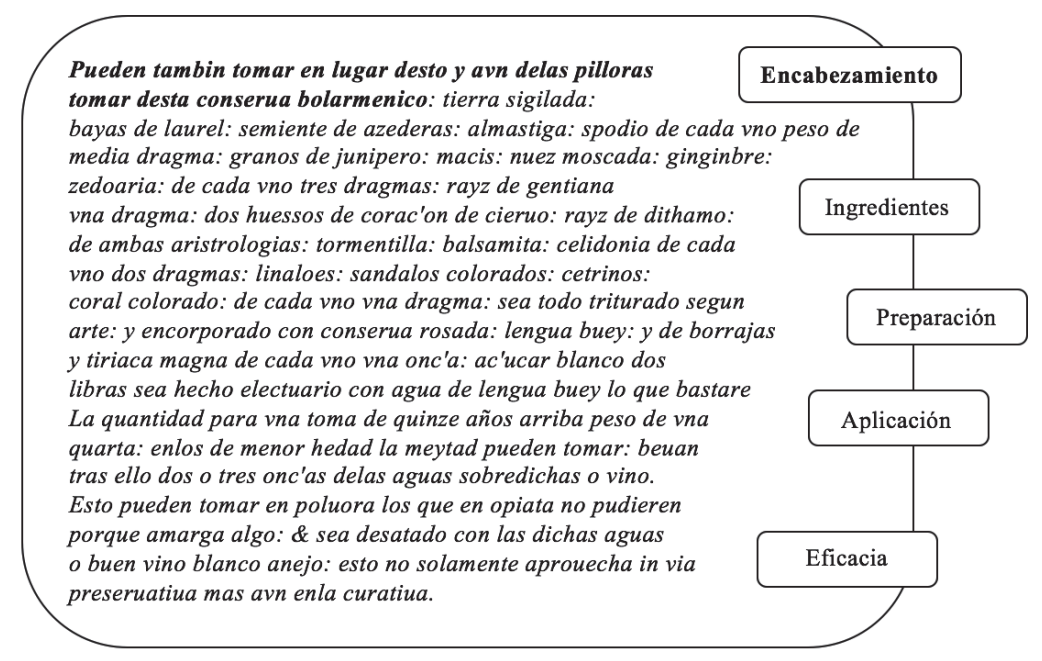

Figura 4. Etapas de una receta incluida en un tratado de peste

Como observamos en la figura anterior, la receta contiene los elementos típicos del género discursivo (ingredientes, preparación, aplicación, eficacia), pero no forma parte de un recetario; por lo tanto, se incorpora de otra forma en el texto.

Por último, algo que tienen en común tanto los tratados de medicina producidos por médicos eruditos, como el citado Damián Carbón en su Lib.Com. (1541), pero también los recetarios, destinados a otro público y elaborados con otra finalidad, como el Lib.Rec. (1471), es el uso de cláusulas condicionales ${ }^{27}$ que apuntan hacia la posibilidad de que el lector, ya sea como paciente o como curador, necesite una receta en particular para tratar un mal específico:

35. iten si oviere grand dolor en

la cabeça por que non pueda dormjr

faz vngunto de açeite rrosado peuçeano

\& castorio \& vnta la cabeça

\& sana el dolor \& dormjra giluertus

jn lybro pasionario (Lib.Rec., 1471, fol. 5r).

36. Y si fuere con estipticidad del

vientre: denle vna melezina desta forma. Maluas paritaria

calendula hojas de laurel saluado sal de cada

vno vn poco simiente de ynojo camomilla tanto de cada

vno como fuere menester saluado vn poco sal. Todo

sea cozido y colado: (Lib.Com., 1541, fol. 40r).

37. Y si esto no vale vntar le han de

este otro linimento el vientre baxo el ombligo.

Recipe [...]. (Lib.Com., 1541, fol. 35r).

$27 \quad$ Igual sucede en las recetas en inglés medio estudiadas por Alonso-Almeida (1998-1999) y en los regimientos de peste en castellano de la Baja Edad Media analizados por Eberenz (2001). 
En el Lib.Com. (1541), además, estas estructuras se usan también para anticipar la posibilidad de que un remedio no sea efectivo, por lo cual le dan más opciones al destinatario (ejemplo 37). Por el contrario, en el Lib.Rec. (1471), en tanto recetario, las recetas están cohesionadas mediante el conector latino iten (variante formal de item), independientemente de si presentan cláusulas condicionales o no.

\section{Conclusiones}

En este artículo hemos analizado la configuración textual de una serie de recetas médicas presentes en diferentes obras de medicina de finales de la Edad Media y de principios del Renacimiento, correspondientes al período de la lengua conocido como español medio. Nos hemos enfocado en las etapas textuales presentes en las recetas (ingredientes, preparación, aplicación, eficacia), en el uso de determinadas tiempos y modos verbales y en las diferentes estrategias de incorporación de las recetas dentro del texto. A partir de este análisis, presentamos las siguientes conclusiones.

Muchos elementos dependen del carácter de la obra, ya sea este erudito o bien extraacadémico. Por ejemplo, las recetas que forman parte de recetarios o que se encuentran en secciones de recopilación de recetas tienden a presentar la información de manera más imprecisa y escueta. Esto se debe a que son textos pensados para la consulta rápida e inmediata de un remedio en específico. Los libros de carácter erudito, por el contrario, despliegan más información y son más específicos, por lo cual tienden a indicar la cantidad exacta de los ingredientes y de la dosificación. En estas obras, es más importante demostrar el dominio del conocimiento médico, lo cual también se observa en los regimientos de peste de autor conocido (sobre este último punto, véase De la Cruz Cabanillas y Serrano Larráyoz, 2017, p. 11).

Si bien todas las recetas se caracterizan por la mezcla de formas verbales, determinamos algunas tendencias en su empleo. Las recetas prototípicas, es decir, las de los recetarios y de pasajes de recetas, usan sobre todo el modo imperativo en segunda persona singular, como ya ha sido señalado. Las obras de medicina que tratan otros temas, pero incluyen recetas, presentan más variedad en el empleo de tiempos y modos verbales y utilizan otras formas, como el infinitivo y las perífrasis con el verbo poder, lo cual se relaciona con la función de dar consejos y recomendaciones, más que proveer una simple lista de instrucciones. Además, observamos que en todos los textos el uso del modo subjuntivo, especialmente cuando aparece en tercera persona y en voz pasiva, se relaciona con contextos en donde los autores están citando otra fuente, ya sea de manera explícita o implícita.

Por último, a pesar del bajo nivel de alfabetización de la época, lo cual implica que muy pocas personas podían leer estas obras, vemos que la inserción de promesas de eficacia al final de las recetas y la incorporación de las recetas mediante títulos que tematizan los síntomas por combatir o los beneficios del medicamento por preparar dejan claro que el enfoque de la receta médica está en la curación inmediata de la enfermedad. Es decir, están dirigidas a un público al que no le interesa el conocimiento teórico de la medicina, sino que busca una referencia para tratar un malestar de manera simple y exitosa. 


\section{Bibliografía}

\section{Ediciones de textos}

Becker, J. (Ed.). (2012). Libro de medecina llamado macer. En Spanish Medical Texts. Digital Library of Old Spanish Texts. Hispanic Seminary of Medieval Studies. Recuperado de http://www.hispanicseminary.org/t\&c/med/index-en.htm.

Capuano, T. M. (Ed.). (2012). Tratado contra toda pestilencia \& ayre corrupto. En Spanish Medical Texts. Digital Library of Old Spanish Texts. Hispanic Seminary of Medieval Studies. Recuperado de http://www.hispanicseminary.org/t\&c/med/index-en.htm.

González de Fauve, M. E. (Ed.). (2012). Breve tratado de peste. En Spanish Medical Texts. Digital Library of Old Spanish Texts. Hispanic Seminary of Medieval Studies. Recuperado de http://www.hispanicseminary.org/t\&c/med/index-en.htm.

Herrera, M. T. (Ed.). (2012). Compendio de la humana salud. En Spanish Medical Texts. Digital Library of Old Spanish Texts. Hispanic Seminary of Medieval Studies. Recuperado de http://www.hispanicseminary.org/t\&c/med/index-en.htm.

Jiménez Ríos, E. (Ed.). (2012). Secretos de la medicina. En Spanish Medical Texts. Digital Library of Old Spanish Texts. Hispanic Seminary of Medieval Studies. Recuperado de http://www.hispanicseminary.org/t\&c/med/index-es.htm.

Piñeyrua, A. (Ed.). (2012). Libro del arte de las comadres o madrinas y del regimiento de las preñadas y paridas y de los niños. En Spanish Medical Texts. Digital Library of Old Spanish Texts. Hispanic Seminary of Medieval Studies. Recuperado de http://www. hispanicseminary.org/t\&c/med/index-en.htm.

Zurrón, I. (Ed.). (2012). El libro de recetas. En Spanish Medical Texts. Digital Library of Old Spanish Texts. Hispanic Seminary of Medieval Studies. Recuperado de http://www. hispanicseminary.org/t\&c/med/index-en.htm.

\section{Fuentes secundarias}

Alonso-Almeida, F. (1998-1999). "Gyf hyr pis medycyn": Analysing the Middle-English Recipe Medical Discourse. Revista de Lenguas para Fines Específicos, (5-6), 49-81.

Bator, M. (2017). How (im)precise can a cook be? The case of medieval English recipes. Medioevo Europeo, 1(1), 5-16.

Bator, M. y Sylwanowicz, M. (2017). Measures in Medieval English Recipes - Culinary vs. Medical. Studia Anglica Posnaniensia, 52(1), 21-52.

Carroll, R. (1999). The Middle English recipe as a text-type. Neuphilologische Mitteilungen, $100,27-42$.

Carroll, R. (2004). Middle English recipes: Vernacularization of a text-type. En I. Taavitsainen y P. Pahta (Eds.), Medical and scientific writing in Late Medieval English (pp. 174196). Cambridge: Cambridge University Press.

Cruz Volio, G. (2018). Funciones discursivas del latín: code-switching en textos de medicina españoles. Revista de Filología y Lingüística de la Universidad de Costa Rica, 44(1), 145-166. 
Cruz Volio, G. (En prensa). Prácticas definicionales en textos de medicina españoles (siglos XV y XVI). Káñina, Revista de Artes y Letras de la Universidad de Costa Rica.

De la Cruz Cabanillas, I. y Serrano Larráyoz, F. (2017). «For pe goute a good medicyne» / «Otra recepta para la gota»: análisis contrastivo de recetas inglesas y castellanas bajomedievales. Memorabilia, 19, 1-16.

Eberenz, R. (2001). Los regimientos de peste a fines de la Edad Media: configuración de un nuevo género textual. En D. Jacob y J. Kabatek (Eds.), La lengua medieval y tradiciones discursivas en la Península Ibérica (pp. 79-96). Frankfurt / Madrid: Verfuert / Iberoamericana.

Eberenz R. (2009). La periodización de la historia morfosintáctica del español: propuestas y aportaciones recientes. Cahiers d'études hispaniques médiévales, 32, 181-201.

Eberenz, R. (2016). De lo crudo a lo cocinado: sobre el léxico fundamental de la culinaria en la historia del español (siglos XIII a XVII). Revista de Filología Española, 96(1), 81-112.

Gago Jover, F., Herrera, M. T., y González de Fauve, M. E. (2015). HSMS: Digital Library of Old Spanish Texts. Recuperado de http://www.hispanicseminary.org/t\&c/med/index-en.htm

Gallego-Caminero, G., Miró-Bonet, M., Ferrer de Sant Jordi, P. y Gastaldo, D. (2005). Las parteras y / o comadronas del siglo XVI: el manual de Damiá Carbo. Texto \& Contexto Enfermagem, 14(4), 601-607.

Girón Alconchel, J. L. (2005). Cambios gramaticales en los Siglos de Oro. En R. Cano (Coord.), Historia de la lengua española (2 ed.) (pp. 859-894). Barcelona: Ariel.

Görlach, M. (2004). Text types and the history of English. Berlin / New York: Mouton de Gruyter.

Gutiérrez Rodilla, B. (1998). La ciencia empieza en la palabra. Análisis e historia del lenguaje científico. Barcelona: Ediciones Península.

Gutiérrez Rodilla, B.M. (2009). La adecuación lingüística al destinatario en los textos médicos instructivos y de divulgación del renacimiento castellano. Res Diachronicae, 7, 37-46.

Halliday, M. A. K. y Matthiessen, C. M. I. M. (2006). Construing Experience Through Meaning. A Language-based Approach to Cognition. London / New York: Continuum.

Hyland, K. (2007). Applying a Gloss: Exemplifying and Reformulating in Academic Discourse. Applied Linguistics, 28(2), 266-285.

Jucker, A. H. (2008). Historical pragmatics. Language and Linguistics Compass, 2(5), 894-906.

Kabatek, J. (2008). Introducción. En J. Kabatek (Ed.), Sintaxis histórica del español y cambio lingüístico: Nuevas perspectivas desde las Tradiciones Discursivas (pp. 1-7). Madrid / Frankfurt: Iberoamericana / Vervuert.

Lapesa, R. (2008). Historia de la lengua española. Gredos: Madrid.

Lleal, C. (Directora). (2020). DiCCA XV-Diccionario del castellano del siglo XV en la Corona de Aragón. Recuperado de http://ghcl.ub.edu/diccaxv/home/index/myLanguage:es.

Mäkinen, M. (2011). Efficacy phrases in Early Modern English medical recipes. En I. Taavitsainen y P. Pahta (Eds.), Medical Writing in Early Modern English (pp. 158179). Cambridge: Cambridge University Press. 
Marqués-Aguado, T. (2014). The Medical Recipes in the Antidotary in GUL MS Hunter 513 (ff. 37v-96v). Alicante Journal of English Studies, 27, 107-124.

Marqués-Aguado, T. (2018). "A good Receipt to purge": The Medical Recipes in London, Wellcome Library, MS 8086. Complutense Journal of English Studies, 26, 241-262.

Oesterreicher, W. (2005). Textos entre inmediatez comunicativa y distancia comunicativas. El problema de lo hablado escrito en el Siglo de Oro. En R. Cano (Coord.), Historia de la lengua española (2 ed.) (pp. 729-770). Barcelona: Ariel.

Ortiz, T. (1993). From hegemony to subordination: midwives in Early Modern Spain. En H. Marland (Ed.), The art of midwifery: Early modern midwives in Europe (pp. 95-114). London: Routledge.

Pensado Figueiras, J. (2014). Textos médicos extraacadémicos: Difusión de pronósticos, recetarios, herbarios y tratados de alimentos medievales en romance peninsular. Signa, 23, 43-66.

Real Academia Española. (1726-1739). Diccionario de la lengua castellana, en que se explica el verdadero sentido de las voces, su naturaleza y calidad, con las phrases o modos de hablar, los proverbios o refranes, y otras cosas convenientes al uso de la lengua [...]. Compuesto por la Real Academia Española. Madrid: Imprenta Francisco Hierro. Recuperado de http://web.frl.es/DA.html.

Santiago, R. (2005). La historia textual: textos literarios y no literarios. En R. Cano (Coord.), Historia de la lengua española (2 ed.) (pp. 533-570). Barcelona: Ariel.

Schrott, A. (2017). Las tradiciones discursivas, la pragmalingüística y la lingüística del discurso. Revista de la Academia Nacional de Letras, 13, 25-57.

Siraisi, N. (1990). Medieval and Early Renaissance Medicine: An Introduction to Knowledge and Practice. Chicago: University of Chicago Press.

Solomon, M. (2010). Fictions of Well-Being: Sickly Readers and Vernacular Medical Writing in Late Medieval and Early Modern Spain. Philadelphia: University of Pennsylvania Press.

Sylwanowicz, M. (2018). Middle and Early Modern English Medical Recipes: Some Notes on Specialised Terminology. ANGLICA. An International Journal of English Studies, 27(2), 89-101.

Taavitsainen, I. (2001). Middle English recipes: Genre characteristics, text type features and underlying traditions of writing. Journal of Historical Pragmatics, 2, 85-113.

Taavitsainen, I. (2006). Audience Guidance and Learned Medical Writing in Late Medieval English. En M. Gotti y F. Salager-Meyer (Eds.), Advances in Medical Discourse Analysis: Oral and Written Contexts (pp. 431-456). Bern: Peter Lang.

Taavitsainen, I. y Fitzmaurice, S. M. (2007). Historical pragmatics: What it is and how to do it. En S. M. Fitzmaurice e I. Taavitsainen (Eds.), Methods in Historical Pragmatics (pp. 11-36). Berlin: Mouton de Gruyter.

Taavitsainen, I. y Jucker, A. H. (2010). Trends and developments in historical pragmatics. En A. H. Jucker e I. Taavitsainen (Eds.), Handbook of Historical Pragmatics (pp. 3-32). Berlin: Mouton de Gruyter. 
